\section{Effect of intravenous iron supplementation on iron stores in non-anemic iron-deficient patients with hereditary hemorrhagic telangiectasia}

\author{
Torbjörn Karlsson, Honar Cherif \\ Department of Hematology and Center \\ for Osler's Disease, Uppsala University \\ Hospital, Uppsala, Sweden
}

\begin{abstract}
In hereditary hemorrhagic telangiectasia (HHT), frequent episodes of nasal and gastrointestinal bleeding commonly lead to irondeficiency with or without anemia. In the retrospective study presented here we assessed the iron stores, as determined by analysis of plasma ferritin, during oral and intravenous iron supplementation, respectively, in a population of iron-deficient non-anemic HHT patients who were inadequately iron-repleted by oral supplementation. A switch from oral to intravenous iron supplementation was associated with a significant increase in ferritin in this patient population.
\end{abstract}

\section{Introduction}

Hereditary hemorrhagic telangiectasia (HHT) or Osler's disease is an autosomal dominant genetic disorder afflicting approximately one in five thousand individuals. ${ }^{1}$ The pathogenetic basis of the disease is development of vascular malformations in different tissues and organs of the body. ${ }^{1}$ The vascular malformations lead to frequent nasal and gastrointestinal hemorrhagic episodes as well as cardiac, pulmonary and neurological complications. ${ }^{1}$ The diagnosis is based on the presence of the following characteristics: recurrent nose bleeds, mucocutaneous telangiectasias, evidence of autosomal dominant inheritance, and visceral arteriovenous malformations. ${ }^{2,3} \mathrm{~A}$ patient is classified as suffering from HHT if at least three criteria are present. The disease is suspected if a patient presents with two of these criteria, and is considered unlikely if only one criterion is fulfilled. ${ }^{2,3}$ Chronic recurrent hemorrhagic episodes, which are associated with a decreased quality of life,,$^{4,5}$ result in iron deficiency with or without anemia. In iron deficiency, iron is commonly supplemented orally, but may be associated with increased gastrointestinal side effects. ${ }^{6}$ As an alternative to oral supplementation, iron can be administered intravenously (IV).$^{7,8}$

\section{Materials and Methods}

At the Center for Osler's Disease, Uppsala University Hospital, Sweden, one of our treatment goals is to prevent anemia in the patients by means of iron supplementation and erythropoiesis-stimulating agents. In non-anemic patients we aim at keeping the patients iron replete, that is, ferritin $>100 \mu \mathrm{g} / \mathrm{L} .{ }^{9}$ We have identified four female non-anemic HHT patients who never have reached the target ferritin $>100 \mu \mathrm{g} / \mathrm{L}$. They all suffered from frequent nose bleeds, and none of them tolerated more than 100-200 mg of oral ferrous sulphate daily, mainly due to gastrointestinal side effects. During 2013-2015 they were switched from oral to IV (ferric carboxymaltose or iron isomaltoside 1000) iron. Since the treatment was outside the clinical trial setting, dosing was individualized for each patient. The aim of this retrospective study was to evaluate whether a switch from oral to IV iron in nonanemic HHT patients was associated with a significant increase in patient iron stores as determined by analysis of plasma ferritin. Hemoglobin (Hb), mean corpuscular volume (MCV) and mean corpuscular hemoglobin $(\mathrm{MCH})$ were also analyzed during oral and IV iron supplementation, respectively. In addition, the mean weekly dose of intravenous iron administered was calculated. At our laboratory the $\mathrm{Hb}$ reference range for women is $120-150$ $\mathrm{g} / \mathrm{L}$. For MCV and MCH, reference ranges are 82-98 fL and 27-33 pg, respectively. The ferritin reference range for women is $10-155 \mu \mathrm{g} / \mathrm{L}$. The case records for the patients were reviewed, and the mean values for $\mathrm{Hb}, \mathrm{MCV}, \mathrm{MCH}$ and ferritin were compared during oral and IV iron supplementation. Data were collected for a median of 8.5 (range 5-31) months during oral supplementation and of 3 (range 2-10) months during IV iron supplementation, respectively. This study was approved by the Regulatory Ethics Committee of Uppsala and performed in accordance with the Declaration of Helsinki. Written informed consent was obtained from all patients. Statistical analyses were performed using the SigmaPlot 11 software (Systat Software, San Jose, CA, USA). Quantitative variables were expressed as medians (range) or means \pm standard deviations. The Student's $t$ test or Mann-Whitney rank sum test was used to compare variables. A P-value less than 0.05 was considered statistically significant.
Correspondence: Torbjörn Karlsson, Department of Hematology, Uppsala University Hospital, 75185 Uppsala, Sweden.

Tel.: +46.18.6114401 - Fax: +46.18.502916.

E-mail: torbjorn.a.karlsson@akademiska.se

Key words: Iron deficiency; hereditary hemorrhagic telangiectasia.

Contributions: the authors contributed equally.

Conflict of interest: the authors declare no potential conflict of interest.

Received for publication: 3 December 2015.

Revision received: 5 March 2016.

Accepted for publication: 8 March 2016.

This work is licensed under a Creative Commons Attribution-NonCommercial 4.0 International License (CC BY-NC 4.0).

(c) Copyright T. Karlsson and H.Cherif, 2016

Licensee PAGEPress, Italy

Hematology Reports 2016; 8:6348

doi:10.4081/hr.2016.6348

\section{Results}

The median age of the four female non-anemic HHT patients described here was 57 (range 36-76) years and the median age at diagnosis was 50 (range 24-63) years (Table 1). The switch from oral to IV iron was associated with a significant $(\mathrm{P}<0.001)$ increase in ferritin from 31 to $146 \mu \mathrm{g} / \mathrm{L}$ (Table 2). There were no changes in $\mathrm{Hb}, \mathrm{MCV}$ or MCH after initiation of IV iron supplementation (Table 2). The mean weekly dose of IV iron administered was $56 \mathrm{mg}$.

\section{Discussion}

Absolute iron deficiency is commonly defined as ferritin $<100 \mu \mathrm{g} / \mathrm{L}$ in patients with chronic diseases, for example chronic kidney disease, congestive heart failure and inflammatory bowel disease..$^{10-12}$ Considering HHT as a chronic disease, we aim at keeping our HHT patients above this cut-off by means of iron supplementation, either oral or IV. Although none of the patients suffered from any chronic inflammatory disease, we can not exclude that the ferritin levels observed were influenced by inflammation since ferritin is an acute phase reactant. ${ }^{13}$ We could not properly assess the degree of inflammation biochemically in the 
Table 1. Patient characteristics of the four female non-anemic hereditary hemorrhagic telangiectasia patients switched from oral to intravenous iron.

\begin{tabular}{lccc} 
Patient & $\begin{array}{c}\text { Age, years } \\
\text { Age at diagnosis, } \\
\text { years }\end{array}$ & $\begin{array}{c}\text { HHII-diagnosis } \\
\text { (definite/suspected/unlikely) }\end{array}$ \\
1 & 36 & 24 & Definite \\
2 & 50 & 49 & Definite \\
\hline 3 & 63 & 50 & Suspected \\
4 & 76 & 63 & Definite \\
\hline HHT, hereditary hemorrhagic telangiectasia. & &
\end{tabular}

Table 2. Laboratory data for the patients during oral and intravenous iron supplementation. Data are expressed as mean \pm standard deviation.

\begin{tabular}{lccc} 
Parameter & Oral iron & IV iron & P-value \\
$\mathrm{Hb}, \mathrm{g} / \mathrm{L}$ & $133 \pm 6$ & $133 \pm 7$ & NS \\
$\mathrm{MCV}, \mathrm{fL}$ & $93.3 \pm 4.1$ & $94.1 \pm 2.7$ & $\mathrm{NS}$ \\
\hline $\mathrm{MCH}, \mathrm{pg}$ & $31.4 \pm 1.8$ & $31.9 \pm 1.2$ & $\mathrm{NS}$ \\
Ferritin, $\mu \mathrm{g} / \mathrm{L}$ & $31 \pm 11$ & $146 \pm 91$ & $<0.001$ \\
\hline
\end{tabular}

IV, intravenous; Hb, hemoglobin; MCV, mean corpuscular volume; MCH, mean corpuscular hemoglobin; NS, not significant.

patients since C-reactive protein and erythrocyte sedimentation rate were not analyzed, or were analyzed on only few occasions during the observation period. The four patients presented here failed to reach the treatment goal by oral iron supplementation, probably mainly due to a continuous loss of iron exceeding the maximal rate of gastrointestinal iron absorption, but they reached it after switching to IV iron. Traditionally, ferrous sulphate is given orally in doses of 100-200 mg per day in iron deficiency anemia. In a very recent study by Moretti and co-workers, it was shown that administration of ferrous sulphate twice daily at doses of $60 \mathrm{mg}$ or higher was associated with a hepcidin-related decreased iron absorption the following day. ${ }^{14}$ Thus, one cause that possibly contributed to the failure of our patients to achieve the defined ferritin target could be that they were prescribed too high doses with a too frequent administration of iron supplement. Iron supplementation in iron deficiency without anemia has been associated with functional improvement in patients with congestive heart failure, decreased fatigue in females and decreased symptoms in restless leg syndrome. ${ }^{8,15-18}$ The retrospective nature of this study and the small study cohort prevent us from drawing any conclusions as to whether any possible positive subjective effects, for example, decreased fatigue, were associated with the increased ferritin after initiation of IV iron supplementation.

\section{Conclusions}

Iron deficient non-anemic HHT patients who fail to replete their iron stores by oral iron are readily iron-repleted by IV iron supplementation.

\section{References}

1. Begbie ME, Wallace GMF, Shovlin CL. Hereditary hemorrhagic telangiectasia (Osler-Weber-Rendu syndrome): a view for the 21st century. Postgrad Med J 2003;79: 18-24.

2. Guttmacher A, Marchuk D, White R. Hereditary hemorrhagic telangiectasia N Eng J Med 1995;333:918-24.

3. Bayrak-Toydemir P, Mao R, Lewin S, McDonald J. Hereditary hemorrhagic telangiectasia: an overview of diagnosis and management in the molecular era for clinicians. Genet Med 2004;6:175-91.

4. Geisthof U, Heckmann K, D'Amelio R, et al. Health-related quality of life in hereditary hemorrhagic telangiectasia. Otolaryngol Head Neck Surg 2007;136:72633 .

5. Pasculli G, Resta F, Guastamacchia E, et al. Health-related quality of life in rare diseases: hereditary hemorrhagic telangiectasia (HHT) or Rendu-Osler-Weber disease. Qual Life Res 2004;13:1715-23.

6. McDougall I. Strategies for iron supple- mentation: oral versus intravenous. Kidney Int 1999;55:S61-6.

7. Lindgren S, Wikman 0, Befrits $\mathrm{R}$, et al. Intravenous iron sucrose is superior to oral iron sulphate for correcting anaemia and restoring iron stores in IBD patients: a randomized, controlled, evaluator-blind, multicenter study. Scand J Gastroenterol 2009;44:838-45.

8. Birgegård G, Schneider K, Ulfberg J. High incidence of iron depletion and restless leg syndrome (RLS) in regular blood donors: intravenous iron sucrose substitution more effective than oral iron. Vox Sang 2010;99:354-61.

9. Akademiska Sjukhuset. Oslers sjukdom. Available from: http://www.akademiska. se/sv/Verksamheter/0slercentrum/. Accessed: March 2016.

10. McDonagh T, Macdougall I. Iron therapy for the treatment of iron deficiency in chronic heart failure: intravenous or oral? Eur J Heart Fail 2015;17:248-62.

11. Hörl W. Clinical aspects of iron use in the anemia of kidney disease. J Am Soc Nephrol 2007;18:382-93.

12. Gasche C, Berstad A, Befrits R, et al Guidelines on the diagnosis and management of iron deficiency and anemia in inflammatory bowel disease. Inflamm Bowel Dis 2007;13:1545-53.

13. Moore C, Ormseth M, Fuchs H. Causes and significance of markedly elevated serum ferritin levels in an academic medical center. J Clin Rheumatol 2013;19:324-8.

14. Moretti D, Goede J, Zeder C, et al. Oral iron supplements increase hepcidin and decrease iron absorption from daily or twice-daily doses in iron-depleted young women. Blood 2015;126:1981-9.

15. Anker SD, Comin Colet J, Filippatos G, et al. Ferric carboxymaltose in patients with heart failure and iron-deficiency. $\mathrm{N}$ Eng $\mathrm{J}$ Med 2009;361:2436-48.

16. Verdon F, Burnand B, Stubi CI, et al. Iron supplementation for unexplained fatigue in non-anaemic women: double blind randomized placebo trial. Br Med J 2003; 326:1124-7.

17. Krayenbuhl PA, Batteyay E, Breymann C, et al. Intravenous iron for the treatment of fatigue in non-anemic premenopausal women with low serum ferritin concentration. Blood 2011;118:3222-7.

18. Vaucher P, Druais PL, Waldvogel S, Faurat B. Effect of iron supplementation on fatigue in nonanemic menstruating women with low ferritin: a randomized controlled trial. CMAJ 2012;184:1247-53. 